\title{
Electronic Devices Use Association with Psychological Distress and Sleep among Adolescents
}

\author{
Maysoun Atoum ${ }^{1 \star}$, Sami Al-Rawashdeh ${ }^{2}$, Dina Atoum ${ }^{3}$, Hadeel Atoum ${ }^{4}$, Rand Atoum ${ }^{5}$
}

${ }^{1}$ PhD, RN. Teacher, Department of Community and Mental Health Nursing, The Hashemite University, Faculty of Nursing, P.O. Box 330127, Zarqa 13133, JORDAN ${ }^{2} \mathrm{PhD}, \mathrm{RN}$. Associate Professor, Department of Community and Mental Health Nursing, The Hashemite University, Faculty of Nursing, P.O. Box 330127, Zarqa 13133, JORDAN

${ }^{3} \mathrm{PH}$. The Hashemite University, Faculty of Pharmaceutical sciences, Zarqa, JORDAN

${ }^{4} \mathrm{MD}$. The Hashemite University, Faculty of Medicine, Zarqa, JORDAN

${ }^{5} \mathrm{PH}$. Jordan University of Science \& Technology (JUST), Faculty of Pharmacy, Irbid, JORDAN

*Corresponding Author: maysoun_atoum@hu.edu.jo

Citation: Atoum M, Al-Rawashdeh S, Atoum D, Atoum H, Atoum R. Electronic Devices Use Association with Psychological Distress and Sleep among Adolescents. Electron J Gen Med. 2021;18(6):em327. https://doi.org/10.29333/ejgm/11314

ARTICLE INFO

Received: 22 Aug. 2021

Accepted: 5 Oct. 2021

\begin{abstract}
Introduction: Adolescents' electronic devices (e-devices) use is an emerging issue that may influence their emotions and sleep. The relations between e-devices use and psychological distress of stress, anxiety, depression, and sleep in this population are not well examined. This study aimed to describe e-devices use and psychological distress and sleep in a sample of adolescents and examine the relationships between e-devices use and psychological distress and sleep.
\end{abstract}

Design: This descriptive comparative study utilized cross-sectional collected data on e-devices use, psychological distress, and sleep from 485 randomly selected Jordanian adolescents. Descriptive and inferential statistics were used in this study.

Results: About $99 \%$ of the subjects reported using e-devices for a mean of 5 hours/day. Subjects reported an average of 8 hours of sleep /day, though two-thirds of them reported not getting enough sleep. About 17\%, 37.9\%, $20.2 \%$, and $10 \%$ of the subjects had severe to extremely severe levels of stress, anxiety, depression, and moderate to severe insomnia, respectively. The stress and anxiety scores were significantly higher (worse) in high- compared to low- e-devices users. The difference in insomnia scores approached the significance level ( $p 0.06)$, with high edevices users had poorer scores.

Conclusion: E-devices use is a widespread behavior among Jordanian adolescents. This study demonstrated the negative relationship between e-devices use and psychological distress, especially among female adolescents. It supports targeting adolescents' e-devices users to promote their mental health.

Keywords: adolescents, electronic devices, psychological distress, sleep, insomnia

\section{INTRODUCTION}

During the last decade, electronic devices (e-devices) such as smartphones, video games, computers, and tablets have become essential to modern societies [1,2]. Although e-devise use in a reasonable way is beneficial in improving cognitive skills such as intellectual, attentional control, and problemsolving [3-5], but may have several negative consequences if misused [6]. In 2014, the World Health Organization (WHO) has described excessive e-devices use as a risk factor for developing internet addiction, a behavioral problem similar to the compulsive-impulsive spectrum disorder [7]. Furthermore, the WHO's $11^{\text {th }}$ Revision of the International Classification of Diseases (ICD-11) has included gaming disorder as a new disorder [8]. Given the risk of excessive e-device use, experts have suggested controlling screen time for adolescents. For example, the Canadian 24-Hour Movement Guidelines recommend $\leq 2$ hours/day [9] while the American Academy of
Pediatrics limits screen time use to no more than 1 hour or less per day [10].

A systematic review of reviews synthesized the effects of excessive e-devices for young adolescents' health found that higher e-devices are related to various health harms such as adiposity, unhealthy diet, impacts on sleep, social interaction, and adverse psychological effects [11]. Also, excessive edevices use has shown associations with many physical healthrelated problems such as blurred vision and pain in the wrists or neck pain $[12,13]$. Moreover, overuse of e-devices may lead to some psychological or behavioral problems. It may cause maladaptive behavioral difficulties [14]. A systematic review found that excessive e-devices were related a relation with anxiety ( $\beta$ coefficients, .12-.23) and depression ( $\beta$ coefficients, $.15-.48$ ), and stress ( $\beta$ coefficients, .10 to .30) [15]. This problematic e-devices usage has been reported to be associated with the duration of e-devices use [16].

E-devices addiction also may affect the quality of adolescents' sleep $[17,18]$ and may lead to insomnia $[19,20]$. 
Poor sleep quality has arisen as a related public health problem among e-devices users [21]. The National Sleep Foundation and the American Academy of Sleep Medicine recommend sleeping 8 to 10 hours/day to promote optimal health and support healthy development $[9,22]$. E-devices use at bedtime may impact subsequent sleep through the melatoninsuppression effect and to the increase of pre-sleep psychophysiological arousal secondary to the meeting and content of the media screen time and bedtime [23]. In turn insomnia and poor sleep quality have shown association with an increased risk for the development of major depressive disorder (odds ratio 2.1) [24].

Past existing studies have focused on identifying the links between e-devices and psychological symptoms [15,17], edevices and sleep problems $[16,25,26]$, the addiction of edevices $[18,19]$, or developing, evaluation instruments for various e-device addiction [27-30]. The widespread use of edevices during the Coronavirus disease pandemic, adolescents are likely to use e-devices for more hours per day. Despite the widespread use of e-devices and society, only a few published reports have examined the relations between the use of edevices and adolescents' psychological health. Therefore, this study aimed to describe the effects of e-devices use, depression, anxiety, stress, and sleep in a sample of Jordanian adolescents and examine the associations between e-devices use and depression, anxiety, stress sleep, and sleep. We were also interested in the differences in e-devices use and variables of psychological distress and sleep between males and females in adolescents.

\section{METHODS}

\section{Design}

This study is a cross-sectional descriptive comparative study.

\section{Sample, Sampling, and Settings}

The target population of this study was adolescents aged 15-17 years old. A multiple-stage cluster sampling technique was used to select the study sample among the five educational districts in Amman, Jordan's capital. One region in Amman was chosen randomly. Then, two schools (one for males and another for females) from a list of all government schools were randomly selected. After that, random selection was employed to choose two classes from each $9^{\text {th- }}, 10^{\text {th }}$, and $11^{\text {th }}$-grade level in each school. Only students in the selected classes were invited to participate. The final sample consisted of 235 male and 250 female students drawn out of 1,210 males and 1,380 female students in the two schools. The study participants' sample size was calculated using the $G^{\star}$ Power 3.1.2. Analysis using a conventional value of statistical significance $(\alpha)$ of .05 , a power level of 0.80 , and a small effect size of 0.2 , for two-tailed test and using the statistical test of ttest, the required sample size was about 410 students. We invited 100 additional participants to overcome the expected non-response rate of $25 \%$ and issues associated with having the consent of both students and their parents.

\section{Procedure}

The Ethics Committee of the Institutional Review Board (IRB) at the university where the first two authors are working (reference\# 5/2/2018/2019) and the Ministry of Education-
Jordan approved this study. Before data collection, the purpose of the study was briefly described to the students and their parents then written consents were obtained from both students and their parents. All participants were assured that they have the right to participate, refuse, and withdraw at any time without any consequence and that their confidentiality will be maintained. Participants were given questionnaires and instructed to return questionnaires using the provided sealed envelope to the researcher or the teachers. Data were collected in the academic year of 2018/2019.

\section{Measures}

In addition to the questionnaires on variables of e-devices use, psychological distress, and insomnia, a demographic sheet developed for this study was used to collect the respondents' socio-demographic and clinical characteristics. The data collected includes age, gender, number of family members, educational level of parents, and monthly income.

E-devices use. Subjects' e-devices use was assessed using two questions. The first question asked whether they use edevices such as smartphones, video game consoles, computers, and tablets or not (responses were either yes or no). The second question asked about the average duration of the e-devices use per day.

Psychological distress. Psychological distress was measured using the Arabic version of the Depression Anxiety Stress Scale-21 (DASS-21) short form. The DASS-21 is a selfreport questionnaire consisting of 21 items with each pertinent seven items measure one dimension of mental health symptoms of depression, anxiety, or stress [31]. The responses of the items ranged from 0 (does not apply to me at all) to 3 (referred to me very much). The total score of each dimension is calculated by summing the scores of the seven items then multiplying them by two, with the subscales score can range between 0 and 42 and with higher scores indicating severe mental health symptoms. Summing the scores of the three dimensions yields a total score for the whole scale, which can be ranged between 0 to 126 . The validity and reliability of the DASS-21 questionnaire in measuring the dimensions of depression, anxiety, and stress have been provided in several studies [32-34]. In the original study, DASS-21 indicated good internal consistency in which the Cronbach alpha was .74, .75, .73 , and .80 for depression, anxiety, stress, and the total scale, respectively [31]. In the current study, Cronbach's reliability alphas were $0.71,0.63,0.67$, and 0.83 for the stress, anxiety, depression subscales, and the total scale scores, respectively.

sleep. Subjects' sleep was measured using questions on participants' sleep duration (on average hours of sleep /night), perception of the adequacy of their sleep (adequate or not), taking a nap during the day (yes or no), and duration of the nap (on average hours/day, if applicable). Also, we measured insomnia as part of the subject's sleep assessment using the Insomnia Severity Index (ISI). The ISI is a widely used 7-item self-report questionnaire measuring the nature, severity, and effect of insomnia. The ISI asks respondents to answer the items related to sleep problems on a 5-point Likert scale ranging from 0 "not at all" to 4 "very severe." The total scores were calculated by summing the responses of the items with total scores ranging from 0 to 28 , with higher scores indicating severe Insomnia. The respondents were categorized based on the cutoff scores of $0-7,8-14,15-21$, and $22-28$ into no insomnia, mild insomnia, moderate insomnia, and severe insomnia, respectively [20]. The ISI showed excellent 
Table 1. Demographic characteristics of the sample $(\mathrm{N}=485)$

\begin{tabular}{|c|c|}
\hline Characteristic & Mean \pm SD or $n(\%) \dagger$ \\
\hline Age, Years & $16.09 \pm 0.77$ \\
\hline \multicolumn{2}{|l|}{ Gender } \\
\hline Female & $250(51.5)$ \\
\hline Male & $235(48.5)$ \\
\hline Number of Family Members & $4.76 \pm 1.259$ \\
\hline \multicolumn{2}{|l|}{ Family Income } \\
\hline$\leq \$ 400$ & $40(8.2)$ \\
\hline$\$ 401-800$ & 203 (41.9) \\
\hline$\$ 801-1200$ & $140(28.9)$ \\
\hline$>\$ 1201$ & $102(21)$ \\
\hline \multicolumn{2}{|l|}{ Fathers Level of Education } \\
\hline$\leq$ Primary level & $66(13.6)$ \\
\hline High school level & $180(37.1)$ \\
\hline Diploma le vel & $99(20.4)$ \\
\hline$\geq$ University level & $140(28.8)$ \\
\hline \multicolumn{2}{|l|}{ Mothers Level of Education } \\
\hline$\leq$ Primary level & $57(11.7)$ \\
\hline High school level & $229(47.2)$ \\
\hline Diploma level & $111(22.9)$ \\
\hline$\geq$ University level & $88(18.1)$ \\
\hline \multicolumn{2}{|l|}{ BMI } \\
\hline Underweight (<19) & $23(4.7)$ \\
\hline Normal (19-25) & $396(76.1)$ \\
\hline Overweight (>25-30) & $70(14.4)$ \\
\hline Obese $(>30)$ & $23(4.7)$ \\
\hline
\end{tabular}

†SD = standard deviation

psychometric properties and was validated in the adolescent population $[35,36]$. The Arabic version of the ISI has shown excellent psychometric properties as well $[37,38]$. In the current study, the ISI had a Cronbach's alpha of 0.72 .

\section{Data Analysis}

Data analysis was conducted using SPSS version 25 with 0.05 as the significance level. Data analyses including descriptive statistics such as frequency, percentage, mean, standard deviation, as appropriate to the level of measurement, were used to describe the sociodemographic and clinical characteristics of the participants. Subjects were classified based on their scores on psychological distress (stress, anxiety, and depression) into normal, mild, moderate, and severe to extremely severe based on the cut-off scores of 0-14, 15-18, 19-25, and $>25$ for stress subscale, 0-7, 8-9, 10-14, and $>14$ for anxiety subscale, and 0-9, 10-13, 14-20, and $>20$ for the depression subscale, respectively. To examine the relations between using e-devices with psychological distress and insomnia, subjects were divided into two groups based on the mean hours of using e-devices per day. Those who had below the mean were classified as low e-devices users and those who had scores higher than the mean were classified as high edevices users. The Independent Sample t-tests were used to compare psychological distress and sleep scores between low and high e-device users as well as to compare males and females regarding their e-devices use, sleep, and psychological distress.

\section{RESULTS}

\section{The Subjects' Characteristics and Scores on Main Study Variables}

The subject's mean age was about 16 years, with a range of 15-18 years (Table 1 ). Slightly more than half of the subjects
Table 2. The sample's data on e-devices use, psychological distress, and sleep ( $\mathrm{N}=485)$

\begin{tabular}{lc}
\hline Characteristic & Mean \pm SD or $\mathbf{n}$ (\%)† \\
\hline Use e-devices, Yes & $478(98.6)$ \\
\hline Average hours of screen-time/day & $5.26 \pm 4.0$ \\
\hline Average hours of sleep/day & $8.06 \pm 1.88$ \\
\hline Perceived get an adequate amount of sleep, Yes & $165(34)$ \\
\hline Taking a nap time, Yes & $240(49.5)$ \\
\hline Duration of the nap, minutes & $35.55 \pm 41.79$ \\
\hline Duration of the nap, min-max in Minutes & $10-120$ \\
\hline Insomnia Severity Index scores & $8.75 \pm 4.57$ \\
\hline Insomnia Severity Index Categories & \\
No insomnia (0-7) & $222(45.8)$ \\
Subthreshold/mild (8-14) & $212(43.7)$ \\
Moderate to severe (>14) & $51(10.5)$ \\
\hline Psychological distress (DASS-21) & \\
Total scores & $42.49 \pm 20.3$ \\
Stress subscale scores & $15.73 \pm 8.74$ \\
Anxiety subscale scores & $12.95 \pm 7.5$ \\
Depression subscale scores & $13.81 \pm 8.2$ \\
\hline Stress categories (DASS-21) & \\
Normal (0-14) & $255(52.6)$ \\
Mild (15-18) & $63(13)$ \\
Moderate (19-25) & $84(17.3)$ \\
Severe to extremely severe (>25) & $83(17.1)$ \\
\hline Anxiety categories (DASS-21) & \\
Normal (0-7) & $114(23.5)$ \\
Mild (8-9) & $38(7.8)$ \\
Moderate (10-14) & $149(30.7)$ \\
Severe to extremely severe (>14) & $184(37.9)$ \\
\hline Depression categories (DASS-21) & $160(33)$ \\
Normal (0-9) & $79(16.3)$ \\
Mild (10-13) & $148(30.5)$ \\
Moderate (14-20) & $98(20.2)$ \\
Severe to extremely severe (> 20) & \\
\hline DASS 21-Depresson Anxisy Strs & \\
\hline
\end{tabular}

DASS 21= Depression Anxiety Stress Scale - 21; †SD = standard deviation

were male. The average number of family members was 4.76 members. About half of the subjects reported family income of \$401-\$800 per month, and mothers had a high school level of education. One-third of the subjects' fathers had a high school level of education.

Almost all subjects use e-devices (Table 2). Subjects reported using these devices for an average of 5.25 hours per day. On psychological distress, the total scores (total DASS-21), the subjects had an average of about $42.49 \pm 20.3$, mainly indicating mild distress (Table 2). On the psychological subscales, the subjects had mean scores that fell in the category of mild stress, moderate anxiety, and mild depression. As shown in Table 2, about 17\%, 37.9\%, and 20.2\% of the subjects had severe to extremely severe levels of stress, anxiety, and depression, respectively.

Although the subjects reported an average of 8 hours of sleep per day, two-thirds of them reported not getting enough sleep. Besides, half of the subjects answered they took a nap that ranged between 10 minutes to two hours with an average of 35 minutes. Regarding the insomnia scores, the mean scores of the sample were 8.75, which fell in the subthreshold/ mild insomnia category, with only about $10 \%$ reported moderate to severe Insomnia.

\section{Differences between Low and High E-devices Users on Main Study Variables}

Independent Samples t-tests were used to compare low and high e-devices users in terms of total psychological distress 
Table 3. Comparison between low users and high e-devices users ( $\mathrm{N}=485)$

\begin{tabular}{|c|c|c|c|c|}
\hline Characteristic & $\begin{array}{l}\text { Low e-device users } \\
(n=346) \dagger\end{array}$ & $\begin{array}{c}\text { High e-devices users } \\
(n=139) \dagger\end{array}$ & t- test (df1, 483) & $\begin{array}{c}\text { P-value } \\
\text { (2-tailed) }\end{array}$ \\
\hline Insomnia severity Index scores & $8.50 \pm 4.44$ & $9.37 \pm 4.85$ & -1.886 & 0.06 \\
\hline Average hours of sleep/day & $7.88 \pm 1.78$ & $8.51 \pm 2.06$ & -1.427 & 0.154 \\
\hline Duration of the nap, Minutes & $37.09 \pm 42.16$ & $31.73 \pm 40.77$ & 1.28 & 0.201 \\
\hline Total DASS-21 scores & $40.34 \pm 19.86$ & $47.87 \pm 20.48$ & -3.087 & 0.002 \\
\hline Stress subscale scores (DASS-21) & $14.77 \pm 8.45$ & $18.11 \pm 9.05$ & -3.348 & .001 \\
\hline Anxiety subscale scores (DASS-21) & $12.47 \pm 7.37$ & $14.14 \pm 7.72$ & -3.651 & $<0.001$ \\
\hline Depression subscale scores (DASS-21) & $13.08 \pm 8.09$ & $15.61 \pm 8.26$ & -0.922 & 0.357 \\
\hline
\end{tabular}

†Data are presented as mean \pm standard deviation

Table 4. Comparison of Psychological Distress scores and Sleep between male and female adolescents ( $\mathrm{N}=485)$

\begin{tabular}{|c|c|c|c|c|}
\hline Characteristic & $\begin{array}{c}\text { Male } \\
(n=235) \dagger\end{array}$ & Females $(n=250) \dagger$ & t- test (df 1, 483) & $\begin{array}{c}\text { P-value } \\
\text { (2-tailed) }\end{array}$ \\
\hline Average hours of screen-time/day & $4.93 \pm 3.65$ & $5.54 \pm 4.28$ & -1.627 & 0.104 \\
\hline Insomnia severity Index scores & $8.63 \pm 4.33$ & $8.85 \pm 4.79$ & -0.523 & 0.600 \\
\hline Average hours of sleep/day & $7.94 \pm 1.93$ & $8.18 \pm 1.82$ & -1.427 & 0.154 \\
\hline Duration of the nap, Minutes & $33.06 \pm 41.67$ & $37.9 \pm 41.8$ & -1.274 & 0.203 \\
\hline Total DASS-21 scores & $39.51 \pm 18.4$ & $45.29 \pm 21.6$ & -3.162 & 0.002 \\
\hline Stress subscale scores (DASS-21) & $14.37 \pm 8.06$ & $17.0 \pm 9.17$ & -3.348 & 0.001 \\
\hline Anxiety subscale scores (DASS-21) & $11.68 \pm 6.86$ & $14.14 \pm 7.89$ & -3.651 & $<0.001$ \\
\hline Depression subscale scores (DASS-21) & $13.45 \pm 7.89$ & $14.14 \pm 8.5$ & -0.922 & 0.357 \\
\hline
\end{tabular}

$\dagger$ Date are presented as mean \pm standard deviation

scores (total DASS-21), and the subscales scores of stress, anxiety, and depression and the insomnia scores, average hours of sleep/day, duration of the nap. The results showed that only the total psychological distress scores and subscales scores of stress and anxiety differed between the two kinds of users, with those in high e-devices users had poorer scores compared to low e-devices users (Table 3). Although it was not significant, it is interesting to note that the high e-devices users reported sleeping more hours per day than low e-devices users. On the contrary, with regards to insomnia scores, high edevices users reported worse scores than low e-devices users (approaching the significance level, $p=0.06$ ).

\section{Differences between Male and Female Adolescents on Main Study Variables}

Using the independent samples t-tests to compare male and female adolescents in terms of average hours of screentime/day, insomnia scores, average hours of sleep/day, duration of the nap, total psychological distress scores (total DASS-21), and the subscales scores of stress, anxiety, and depression indicated that there were only significant differences between male and female adolescents in the total DASS-21 and the subscales scores of stress and anxiety. Specifically, females had higher (worse) scores on the stress and anxiety subscales scores and the total scores on psychological distress (total DASS-21).

\section{DISCUSSION}

The current study examined the relationship between edevices use, stress, anxiety, depression, and insomnia among adolescents in Jordan. It showed that excessive e-devices use was associated with stress and anxiety, especially among female adolescents. No significant correlation between excessive e-devices use and insomnia was noted in this study.

The majority of subjects in the study used the e-devices for a high duration of time, more than the specific recommendations daily of two hours [9]. The duration of the adolescents' use of e-devices reported in this study is consistent with school-based population studies that confirmed high levels of e-devices use among adolescents $[39,40]$. Similar to our finding, adolescents exposed to excessive e-devices time displayed adverse psychological outcomes $[11,30,41]$. Subjects in our study also had higher scores on psychological distress than those reported in the literature $[42,43]$. For example, subjects in our study had higher psychological distress than Indian [43] and Malaysian adolescents [44].

Excessive use of e-devices has shown to be associated with poorer psychological distress only on the stress and anxiety subscales. These findings were constant with previous research $[45,46]$. Similar to our result a significant relation was found between e-devices use and stress $[17,47,48]$. Each study used a different measure of stress, including the DASS, Perceived Stress Scale (PSS), adapted from Kanner, Coyne, Schaefer, \& Lazarus. The majority of multivariate relations were significant, mostly with betas ranging from .10 to .30 . Similarly, the anxiety subscale was significantly related to edevices use $[15,16,44]$; these studies used the Beck Anxiety Inventory, social anxiety-related scales. Bivariate correlations and multivariate beta coefficients were around 20 .

Our finding is consistent with the result that the high-level duration of e-devices used was significate related to the severity of anxiety but not significant in depression [54]. Only $20 \%$ of the participants have depression symptoms, which was not consistent in a previous national survey in 2018 showed that adolescents have moderate to severe levels of depression with a higher percentage (34\%) [49]. Contrary to previous findings, the depression level was less than many previous studies finding $[45,48,50]$, which find correlations in the severity of depression range of .20-.40. By using the Beck Depression Inventory, Depression Anxiety Stress Scale (DASS), 10-item Center for Epidemiologic Studies Depression scale. However, these differences could be related to using different instruments for measuring these concepts. 
Unfortunately, spending more time on e-devices use may not be a helpful way to cope. Also, it is possible that using edevices, especially for a long duration of time, may provoke negative emotions such as stress, anxiety, or depression and may lead to addiction. This cycle could further worsen psychological symptoms, initiating or exacerbating psychological well-being [51] and trigger further e-devices use.

The mean sleep duration of approximately eight hours every day showed adequate hours of sleep per day. There was moderate to severe insomnia in the present study, about $10 \%$ depending on the diagnostic test of ISI. Contrary to many other studies show a high rate of insomnia, ranging from $13.6 \%$ to $23.6 \%$, depending on diagnostic criteria $[16,52,53]$. Females had a significantly higher prevalence of insomnia than male adolescents. Although many previous studies found that adolescents who reported excessive e-devices use had psychological distress and sleep problems [6,45,48,54], our finding revealed that adolescents had only psychological problems but not sleep problems. And sleep variables were calculated based on self-report, including bedtime, which would need to be explored in a future study. So, determining the most appropriate intervention requires further investigations.

Similar to our finding revealed that females were reported as having worse psychological distress than their male counterparts $[55,56]$ and females were significantly more addicted to e-devices than their male age group [45,57]. The psychological problems pathways to be hyperactive, and females are more stress-reactive than males due to the variance effect of testosterone hormone hypothalamicpituitary-adrenal axis [58]. Although, other studies reported that the prevalence of psychological distress among adolescent used e-devices was higher in males [42,59], or without differences $[60,61]$. Additionally, the authors suggested a differential sensitivity between male and female adolescents due to Estrogen hormone differences [65].

Significantly, sex differences are manifested not only in the prevalence of the condition but also characterize the comorbidities, precipitating factors of the disorder, especially among females. There is also a need to educate female adolescents' students about the physical and psychological risks of e-devices and their associated applications. A qualitative study will also be required to understand these associations within the Jordanian context in-depth.

This study highlights the connotation between excessive edevices use and adolescents' psychological distress like anxiety, stress, and sleep problems. Our study is in line with a longitudinal study that reported that e-devices use was associated with sleep difficulties related to psychological distress $[11,16,17,62,63]$.

Adolescents with insomnia are more likely to report comorbid psychological distress than adolescents without insomnia [52]. Two meta-analyses of the effect of e-device time on young adolescent's sleep have been conducted [25,64]. The potential mechanisms in troubled sleep may include psychological stimulation [23], poor sleep quality, and insomnia [65-68]; reduction of sleep duration among adolescents can cause gaming disorder [18,69], which may further lead to impact school performance [70].

These associations do not provide evidence on the causative direction between these variables and often concern confounding factors, including socioeconomic grouping and adverse related behaviors [11]. It is possible that adolescents with stress, anxiety, or depression, may spend more time on edevices as a coping mechanism to escape from fears and worries in their life [61,71,72].

\section{Strength and Limitations}

Our study has many strengths, including that the main study variables were measured using reliable and valid tools. Also, we used randomized sampling, which also strengthens the study and helps in generalizing the findings. However, using a cross-sectional design limits examining the causes and effects among study variables. Insomnia as an effect; cannot assess the causality relationships. More longitudinal and experimental studies are needed to allow attribution of causation. Required now are more rigorous prospective investigations of these relations. All variables were evaluated through a self-reported questionnaire, and so the responses might have been subject to reporting bias. It is highly recommended to add objective measures of the variables.

\section{Implications}

The findings of this study have many implications for practice, research, and education. For practice, Adolescents' edevices use, psychological health, and sleep should be frequently and regularly monitored. School health nurses and other care providers such as psychologists, social workers, teachers can collaborate to use a multidisciplinary approach to meet adolescents' psychological health needs in collaboration with adolescents' parents.

Understanding the relationships among e-devices use, sleep, and psychological health is essential when assessing and managing adolescents with the high-risk need for early intervention and necessitate further researcher. Crisis interventions and education programs should target high-risk groups with psychological distress and the well-functioning general population. The findings of our study may raise the points of giving effective collaborative community-based programs to protect this age group.

Designing students' curricula should provide the students with basics principles about e-devices exposure. Psychoeducation training programs, individual or group counseling/therapy, and family/community projects are required for adolescents as early prevention and intervention programs to limit the time of e-devices use and consequently preventing co-related problems pertaining to psychological health, include courses on time management, problem solving skills and finding alternative activities to fill the adolescents' free time with things that are interesting, beneficial, and healthy.

In particular, there is a need for developing policies to inform the design and implementation of a guideline on the effect of e-devices on psychosocial and sleep difficulties for providing support for a similar situation. Also, the finding highlights the e-devices addiction among adolescents, and highlighted the importance of restricting and limiting the total time spent on e-devices and limiting downloading applications, reaching and accessing material online by establishing screen time rules as to international recommendations for screen time [44].

In research, more longitudinal and experimental studies are needed to allow attribution of causation and conduct interventional studies to help adolescents promote their mental health. Replicating this study using representative 
samples from other governmental and private schools in Jordan will enhance the generalizability of the findings. Moreover, a quantitative survey at both the elementary and high school levels is recommended for future research. Although Our finding revealed that the duration of e-devices had a significantly stronger association with psychological symptoms than with sleep problems, a mediation relationship among these variables could explain this and warrants further investigations. Conducting further studies is needed into specific interventions to improve health among adolescents.

The study highlights the need for increasing awareness about the effects of e-devices use problems and their consequences including addiction, sleep, and mental health issues among adolescents by providing education programs on gaming addiction. Given the number of female adolescents who struggle, it is crucial to recognize sex differences in the association between psychological and sleep problems. There is a clear need for clinicians, teachers, parents, and adolescents for more basic, translational, and clinical research examining the effects of e-devices on health and health behavior consequences among adolescents [24]. Therefore, these pieces of information may be significant to meet the health needs of adolescents for building a public support system, preventing and treating mental health through the strengthening of health systems.

\section{Conclusion}

In conclusion, e-devices may have several adverse significant harmful effects. The present study assessed relations between e-devices used with psychological distress among Jordanian adolescents. The results showed that both severities of psychological distress and sleep disruption were positively associated with e-devices use, especially among female subjects.

The data indicate that insomnia and other psychological distress severely influence adolescents' future health and functioning. There are sudden, pre-significant symptoms of psychological distress among adolescents, which happen when excessive e-devices start coming. Psychological distress can also lead to sleep problems and need to be identified and treated appropriately. Psychological and sleep problems have a complex and bidirectional interrelation. In addition, although severities of psychological distress and was more strongly associated with stress and anxiety. Attentions exist for online gaming disorder among Jordanian adolescent.

Thus, as recommended in current guidelines, we should consider both domains of psychological distress and sleep problems when we come across e-devices excessive use, considering the potentially more significant impact of edevices on psychological distress. These data suggest that primary care settings such as schools might provide policies to limit the time spent on e-devices.

Crisis interventions and education programs should target high-risk groups with psychological distress and sleep problems and the well-functioning general population. The findings of our study may raise the points of giving effective collaborative community-based programs to protect this age group. Conducting further studies is needed into specific interventions to improve health with excessive e-devices used among that age group in Jordan and conducting interventional studies to help adolescents in inappropriate use of the edevices.
Author contributions: All authors have sufficiently contributed to the study, and agreed with the results and conclusions.

Funding: No funding source is reported for this study.

Declaration of interest: No conflict of interest is declared by authors.

\section{REFERENCES}

1. The World Health Organization [WHO]. Adolescent mental health. 2020. Available at: https://www.who.int/newsroom/fact-sheets/detail/adolescent-mental-

health\#: :text=Adolescents\%20with\%20mental\%20health \%20conditions, health\%20and\%20human\%20rights\%20vi olations

2. The World Bank. The World Bank. Washington, DC: The World Bank; 2016. World Development Report 2016: Digital Dividends. 2016; Available at: http://www.worldbank.org/ en/publication/wdr2016

3. Nuyens FM, Kuss DJ, Lopez-Fernandez O, Griffiths MD. The empirical analysis of non-problematic video gaming and cognitive skills: A systematic review. Int J Ment Health Add 2019;17(2):389-414. https://doi.org/10.1007/s11469-0189946-0

4. Hisam A, Mashhadi SF, Faheem M, Sohail M, Ikhlaq B, Iqbal I. Does playing video games effect cognitive abilities in Pakistani children? Pak J Med Sci 2018 Nov-Dec;34(6):150711. https://doi.org/10.12669/pjms.346.15532

5. Ozcetin M, Gumustas F, Cag Y, Gokbay IZ, Ozmel A. The relationships between video game experience and cognitive abilities in adolescents. Neuropsychiatr Dis Treat 2019 May 8;15:1171-80. https://doi.org/10.2147/NDT. S206271 PMid:31190825 PMCid:PMC6514119

6. Gottschalk F. Impacts of technology use on children: Exploring literature on the brain, cognition and well-being. 2019. https://doi.org/10.1787/8296464e-en

7. Block JJ. Issues for DSM-V: internet addiction. Am J Psychiatry. 2008 Mar;165(3):306-7. Issues for DSM-V: Internet addiction 2008. https://doi.org/10.1176/ appi.ajp.2007.07101556 PMid:18316427

8. WHO. ICD-11 for Mortality and Morbidity Statistics (Version: 05/2021) Addictive behaviours: Gaming disorder. 2018; Available at: https://icd.who.int/browse11/l-m/en\#/ http://id.who.int/icd/entity/1448597234

9. Janssen I, Roberts KC, Thompson W. Adherence to the 24Hour Movement Guidelines among 10- to 17-year-old Canadians. Health Promot Chronic Dis Prev Can 2017 Nov;37(11):369-75. https://doi.org/10.24095/hpcdp.37.11. 01 PMid:29119774 PMCid:PMC5695900

10. American Academy of Pediatrics (AAP). AAP. (2016). Media and young minds. Pediatrics. 2016. http://doi.org/10.1542/peds.2016-2591 PMid:27940793

11. Stiglic N, Viner RM. Effects of screentime on the health and well-being of children and adolescents: a systematic review of reviews. BMJ Open 2019 Jan 3;9(1):e023191-2018023191. https://doi.org/10.1136/bmjopen-2018-023191 PMid:30606703 PMCid:PMC6326346

12. Alzaid AN, Alshadokhi OA, Alnasyan AY, AlTowairqi MY, Alotaibi TM, Aldossary FH. The prevalence of neck pain and the relationship between prolonged use of electronic devices and neck pain IN: A Saudi Arabia, cross-sectional study in Saudi Arabia. Egypt J Hosp Med 2018;70(11):19929. https://doi.org/10.12816/0044856 
13. Alhassan AA, Alqadhib EM, Taha NW, Alahmari RA, Salam M, Almutairi AF. The relationship between addiction to smartphone usage and depression among adults: a cross sectional study. BMC Psychiatry 2018;18(1):1-8. https://doi.org/10.1186/s12888-018-1745-4 PMid:29801442 PMCid:PMC5970452

14. Billieux J, Maurage P, Lopez-Fernandez O, Kuss DJ, Griffiths MD. Can disordered mobile phone use be considered a behavioral addiction? An update on current evidence and a comprehensive model for future research. Cur Addic Rep 2015;2(2):156-62. https://doi.org/10.1007/s40429-0150054-y

15. Elhai JD, Dvorak RD, Levine JC, Hall BJ. Problematic smartphone use: A conceptual overview and systematic review of relations with anxiety and depression psychopathology. J Affect Disord 2017;207:251-9. https://doi.org/10.1016/j.jad.2016.08.030 PMid:27736736

16. Lee JJ, Wang MP, Luk TT, Guo N, Chan SS, Lam TH. Associations of electronic device use before and after sleep with psychological distress among Chinese adults in Hong Kong: Cross-sectional study. JMIR Mental Health 2020;7(6):e15403. https://doi.org/10.2196/preprints.15403

17. Wang C, Li K, Kim M, Lee S, Seo D. Association between psychological distress and elevated use of electronic devices among US adolescents: Results from the youth risk behavior surveillance 2009-2017. Addict Behav 2019;90:112-8. https://doi.org/10.1016/j.addbeh.2018.10. 037 PMid:30388504

18. Ibrahim NK, Baharoon BS, Banjar WF, Jar AA, Ashor RM, Aman AA, et al. Mobile Phone Addiction and Its Relationship to Sleep Quality and Academic Achievement of Medical Students at King Abdulaziz University, Jeddah, Saudi Arabia. J Res Health Sci 2018 Aug 4;18(3):e00420. https://doi.org/10.31254/jmr.2018.4305

19. Van Deursen AJ, Bolle CL, Hegner SM, Kommers PA. Modeling habitual and addictive smartphone behavior: The role of smartphone usage types, emotional intelligence, social stress, self-regulation, age, and gender. Comput Hum Behav 2015;45:411-20. https://doi.org/10.1016/ j.chb.2014.12.039

20. Morin CM, Belleville G, Bélanger L, Ivers $H$. The Insomnia Severity Index: psychometric indicators to detect insomnia cases and evaluate treatment response. Sleep 2011;34(5):601-8. https://doi.org/10.1093/sleep/34.5.601 PMid:21532953 PMCid:PMC3079939

21. Cheung LM, Wong WS. The effects of insomnia and internet addiction on depression in Hong Kong Chinese adolescents: an exploratory cross - sectional analysis. J Sleep Res 2011;20(2):311-7. https://doi.org/10.1111/j.13652869.2010.00883.x PMid:20819144

22. Paruthi S, Brooks LJ, D’Ambrosio C, Hall WA, Kotagal S, Lloyd RM, et al. Recommended amount of sleep for pediatric populations: a consensus statement of the American Academy of Sleep Medicine. J Cli Sleep Med 2016;12(06):785-6. https://doi.org/10.5664/jcsm.5866 PMid:27250809 PMCid:PMC4877308

23. Hale L, Kirschen GW, LeBourgeois MK, Gradisar M, Garrison MM, Montgomery-Downs $\mathrm{H}$, et al. Youth Screen Media Habits and Sleep: Sleep-Friendly Screen Behavior Recommendations for Clinicians, Educators, and Parents. Child Adolesc Psychiatr Clin N Am 2018 Apr;27(2):229-45. https://doi.org/10.1016/j.chc.2017.11.014 PMid:29502749 PMCid:PMC5839336
24. Baglioni C, Battagliese G, Feige B, Spiegelhalder K, Nissen $C$, Voderholzer $U$, et al. Insomnia as a predictor of depression: a meta-analytic evaluation of longitudinal epidemiological studies. J Affect Disord 2011;135(1-3):10-9. https://doi.org/10.1016/j.jad.2011.01.011 PMid:21300408

25. Carter B, Rees P, Hale L, Bhattacharjee D, Paradkar MS. Association between portable screen-based media device access or use and sleep outcomes: a systematic review and meta-analysis. JAMA pediatrics 2016;170(12):1202-8. https://doi.org/10.1001/jamapediatrics.2016.2341 PMid:27802500 PMCid:PMC5380441

26. Arora T, Broglia E, Thomas GN, Taheri S. Associations between specific technologies and adolescent sleep quantity, sleep quality, and parasomnias. Sleep Med 2014;15(2):240-7. https://doi.org/10.1016/j.sleep.2013.08. 799 PMid:24394730

27. Panayides P, Walker MJ. Evaluation of the psychometric properties of the Internet Addiction Test (IAT) in a sample of Cypriot high school students: The Rasch measurement perspective. 2012. https://doi.org/10.1037/e617822012003 PMCid:PMC3318510

28. Rozgonjuk D, Rosenvald V, Janno S, Täht K. Developing a shorter version of the Estonian smartphone addiction proneness scale (E-SAPS18). Cyberpsychology: J Psy Res Cyberspace 2016;10(4):4. https://doi.org/10.5817/CP20164-4

29. Zhang J, Xin T. Measurement of Internet addiction: an item response analysis approach. Cyberpsychology, Behavior, and Social Networking 2013;16(6):464-8. https://doi.org/10.1089/cyber.2012.0525 PMid:23505969

30. Madigan S, Browne D, Racine N, Mori C, Tough S. Association between screen time and children's performance on a developmental screening test. JAMA pediatrics 2019;173(3):244-50. https://doi.org/10.1001/ jamapediatrics.2018.5056 PMid:30688984 PMCid: PMC6439882

31. Lovibond PF, Lovibond SH. The structure of negative emotional states: Comparison of the Depression Anxiety Stress Scales (DASS) with the Beck Depression and Anxiety Inventories. Behav Res Ther 1995;33(3):335-43. https://doi.org/10.1016/0005-7967(94)00075-U

32. Ali OM, Milstein G. Mental illness recognition and referral practices among imams in the United States. J Muslim Mental Health 2012;6(2):3-13. https://doi.org/10.3998/ jmmh.10381607.0006.202

33. Osman A, Wong JL, Bagge CL, Freedenthal S, Gutierrez PM, Lozano G. The depression anxiety stress Scales - 21 (DASS - 21): further examination of dimensions, scale reliability, and correlates. J Clin Psychol 2012;68(12):132238. https://doi.org/10.1002/jclp.21908 PMid:22930477

34. Singh K, Junnarkar M, Sharma S. Anxiety, stress, depression, and psychosocial functioning of Indian adolescents. Indian J Psychiatry 2015 Oct-Dec;57(4):36774. https://doi.org/10.4103/0019-5545.171841 PMid: 26813517 PMCid:PMC4711236

35. Bastien $\mathrm{CH}$, Vallières $\mathrm{A}$, Morin $\mathrm{CM}$. Validation of the insomnia severity index as an outcome measure for insomnia research. Sleep Med 2001;2(4):297-307. https://doi.org/10.1016/S1389-9457(00)00065-4

36. Chung K, Kan KK, Yeung W. Assessing insomnia in adolescents: comparison of insomnia severity index, Athens insomnia scale and sleep quality index. Sleep Med 2011;12(5):463-470. https://doi.org/10.1016/j.sleep.2010. 09.019 PMid:21493134 
37. Ahmed AE. Validation of Arabic versions of three sleep surveys. Qatar Med J 2015;2014(2):20. https://doi.org/ 10.5339/qmj.2014.20 PMid:25745603 PMCid:PMC4344987

38. Suleiman $\mathrm{KH}$, Yates BC. Translating the insomnia severity index into Arabic. J Nurs Scholar 2011;43(1):49-53. https://doi.org/10.1111/j.1547-5069.2010.01374.x PMid:21342424

39. Séguin D, Klimek V. Just five more minutes please: electronic media use, sleep and behaviour in young children. Early Child Dev Care 2016 06;186(6):981-1000. https://doi.org/10.1080/03004430.2015.1071528

40. Hysing M, Pallesen S, Stormark KM, Jakobsen R, Lundervold AJ, Sivertsen B. Sleep and use of electronic devices in adolescence: results from a large populationbased study. BMJ Open 2015 Feb 2;5(1):e006748-2014006748. https://doi.org/10.1136/bmjopen-2014-006748 PMid:25643702 PMCid:PMC4316480

41. Neophytou E, Manwell LA, Eikelboom R. Effects of excessive screen time on neurodevelopment, learning, memory, mental health, and neurodegeneration: A scoping review. Int J Mental Health Addic 2021;19(3):724-44. https://doi.org/10.1007/s11469-019-00182-2

42. Ostovar S, Allahyar N, Aminpoor H, Moafian F, Nor MBM, Griffiths MD. Internet addiction and its psychosocial risks (depression, anxiety, stress and loneliness) among Iranian adolescents and young adults: A structural equation model in a cross-sectional study. Int $\mathrm{J}$ Mental Health Addic 2016;14(3):257-67. https://doi.org/10.1007/s11469-01900182-2

43. Mishra SK, Srivastava M, Tiwary NK, Kumar A. Prevalence of depression and anxiety among children in rural and suburban areas of Eastern Uttar Pradesh: A cross-sectional study. J Family Med Prim Care 2018 Jan-Feb;7(1):21-6. https://doi.org/10.4103/jfmpc.jfmpc_248_17 PMid:29915728 PMCid:PMC5958570

44. Latiff LA, Tajik E, Ibrahim N, Abubakar AS, Ali, Shirin Shameema Binti Albar. Depression and its associated factors among secondary school students in Malaysia. Southeast Asian J Trop Med Public Health 2016;47(1):131.

45. Demirci K, Akgönül M, Akpinar A. Relationship of smartphone use severity with sleep quality, depression, and anxiety in university students. J Behav Addic 2015;4(2):85-92. https://doi.org/10.1556/2006.4.2015.010 PMid:26132913 PMCid:PMC4500888

46. Samaha M, Hawi NS. Relationships among smartphone addiction, stress, academic performance, and satisfaction with life. Comput Hum Behav 2016;57:321-5. https://doi.org/10.1016/j.chb.2015.12.045

47. Jeong S, Kim H, Yum J, Hwang Y. What type of content are smartphone users addicted to?: SNS vs. games. Comput Hum Behav 2016;54:10-7. https://doi.org/10.1016/ j.chb.2015.07.035

48. Harwood J, Dooley JJ, Scott AJ, Joiner R. Constantly connected-The effects of smart-devices on mental health. Comput Hum Behav 2014;34:267-72. https://doi.org/ 10.1016/j.chb.2014.02.006

49. Dardas LA, Silva SG, Smoski MJ, Noonan D, Simmons LA. The prevalence of depressive symptoms among Arab adolescents: findings from Jordan. Pub Health Nurs 2018;35(2):100-8. PMid:29315784
50. Kim J, Seo M, David P. Alleviating depression only to become problematic mobile phone users: Can face-to-face communication be the antidote? Comput Hum Behav 2015;51:440-7. https://doi.org/10.1016/j.chb.2015.05.030

51. Yen J, Lin H, Chou W, Liu T, Ko C. Associations among resilience, stress, depression, and internet gaming disorder in young adults. Int J Env Res Pub Health 2019;16(17):3181. https://doi.org/10.3390/ijerph16173181 PMid:31480445 PMCid:PMC6747224

52. Hysing $M$, Pallesen S, Stormark KM, Lundervold AJ, Sivertsen B. Sleep patterns and insomnia among adolescents: a population - based study. J Sleep Res 2013;22(5):549-56. https://doi.org/10.1111/jsr.12055 PMid: 23611716

53. Zhao X, Feng X, Garg R, Kelly KM. Reducing late evening bedtime electronic device intentions and use among young adults. Sleep Health 2019;5(4):401-8. https://doi.org/ 10.1016/j.sleh.2019.02.005 PMid:31031180

54. Mei X, Zhou Q, Li X, Jing P, Wang X, Hu Z. Sleep problems in excessive technology use among adolescent: a systemic review and meta-analysis. Sleep Sci Pract 2018;2(1):1-10. https://doi.org/10.1186/s41606-018-0028-9

55. Chen B, Liu F, Ding S, Ying X, Wang L, Wen Y. Gender differences in factors associated with smartphone addiction: a cross-sectional study among medical college students. BMC Psychiatry 2017;17(1):1-9. https://doi.org/10.1186/s12888-017-1503-z PMid:29017482 PMCid:PMC5634822

56. Lin $P$, Lee $Y$, Chen $\mathrm{K}$, Hsieh P, Yang S, Lin Y. The relationship between sleep quality and internet addiction among female college students. Front Neurosci 2019;13:599. https://doi.org/10.3389/fnins.2019.00599 PMid:31249504 PMCid:PMC6582255

57. Tavakolizadeh J, Atarodi A, Ahmadpour S, Pourgheisar A. The prevalence of excessive mobile phone use and its relation with mental health status and demographic factors among the students of Gonabad University of Medical Sciences in 2011-2012. Razavi Int J Med 2014;2(1):e15527. https://doi.org/10.5812/rijm.15527

58. Galvão, Milene de Oliveira Lara, Sinigaglia-Coimbra R, Kawakami SE, Tufik S, Suchecki D. Paradoxical sleep deprivation activates hypothalamic nuclei that regulate food intake and stress response. Psychoneuroendocrinology 2009;34(8):1176-83. https://doi.org/10.1016/j.psyneuen.2009.03.003 PMid:19346078

59. de-Sola J, Talledo H, Rodríguez de Fonseca F, Rubio G. Prevalence of problematic cell phone use in an adult population in Spain as assessed by the Mobile Phone Problem Use Scale (MPPUS). PLoS One 2017;12(8):e0181184. https://doi.org/10.1371/journal.pone .0181184 PMid:28771626 PMCid:PMC5542596

60. Kim H, Min J, Min K, Lee T, Yoo S. Relationship among family environment, self-control, friendship quality, and adolescents' smartphone addiction in South Korea: Findings from nationwide data. Plos One 2018;13(2):e0190896. https://doi.org/10.1371/journal.pone .0190896 PMid:29401496 PMCid:PMC5798771

61. McNicol ML, Thorsteinsson EB. Internet addiction, psychological distress, and coping responses among adolescents and adults. Cyberpsychology Behav Soc Network 2017;20(5):296-304. https://doi.org/10.1089/ cyber.2016.0669 PMid:28414517 PMCid:PMC5485234 
62. Wong HY, Mo HY, Potenza MN, Chan MNM, Lau WM, Chui TK, et al. Relationships between severity of internet gaming disorder, severity of problematic social media use, sleep quality and psychological distress. Int J Env Res Pub Health 2020;17(6):1879. https://doi.org/10.3390/ijerph17061879 PMid:32183188 PMCid:PMC7143464

63. Buabbas AJ, Hasan H, Buabbas MA. The associations between smart device use and psychological distress among secondary and high school students in Kuwait. PLoS One 2021;16(6):e0251479. https://doi.org/10.1371/ journal.pone.0251479 PMid:34129598 PMCid:PMC8205156

64. Bartel KA, Gradisar M, Williamson P. Protective and risk factors for adolescent sleep: a meta-analytic review. Sleep Med Rev 2015;21:72-85. https://doi.org/10.1016/ j.smrv.2014.08.002 PMid:25444442

65. Caumo GH, Spritzer D, Carissimi A, Tonon AC. Exposure to electronic devices and sleep quality in adolescents: A matter of type, duration, and timing. Sleep Health 2020. https://doi.org/10.1016/j.sleh.2019.12.004 PMid:32111524

66. Driller M, Uiga L. The influence of night-time electronic device use on subsequent sleep and propensity to be physically active the following day. Chronobiology International: J Bio Med Rhythm Res 2019 05;36(5):717-24. https://doi.org/10.1080/07420528.2019.1588287 PMid:30889985

67. Li J, Lau JT, Mo PK, Su X, Tang J, Qin Z, et al. Insomnia partially mediated the association between problematic Internet use and depression among secondary school students in China. J Behav Addic 2017;6(4):554-63. https://doi.org/10.1556/2006.6.2017.085 PMid:29280394 PMCid:PMC6034947
68. Mellor D, Hallford DJ, Tan J, Waterhouse M. Sleep competing behaviours among Australian school attending youth: Associations with sleep, mental health and daytime functioning. Int J Psychology 2020 02;55(1):13-21. https://doi.org/10.1002/ijop.12548 PMid: 30525182

69. Alimoradi Z, Lin C, Broström A, Bülow PH, Bajalan Z, Griffiths MD, et al. Internet addiction and sleep problems: A systematic review and meta-analysis. Sleep Med Rev 2019;47:51-61. https://doi.org/10.1016/j.smrv.2019.06.004 PMid:31336284

70. Touitou Y, Touitou D, Reinberg A. Disruption of adolescents' circadian clock: the vicious circle of media use, exposure to light at night, sleep loss and risk behaviors. J Physiology-Paris 2016;110(4):467-79. https://doi.org/10.1016/j.jphysparis.2017.05.001 PMid:28487255

71. Vidal C, Lhaksampa T, Miller L, Platt R. Social media use and depression in adolescents: a scoping review. Int Rev Psychiatry 2020;32(3):235-53. https://doi.org/10.1080/0954 0261.2020.1720623 PMid:32065542 PMCid:PMC7392374

72. Avci D, Kelleci M. Effects of the Anger Coping Programme based on cognitive behavioural techniques on adolescents' anger, aggression and psychological symptoms. Int J Nurs Pract 2016 04;22(2):189. https://doi.org/10.1111/ijn.12410 PMid:26545288 